\title{
Screening of fruit pulp extracts of Picralima nitida against in vitro cultures of Plasmodium falciparum and acute oral toxicity in white albino mice
}

\author{
Samuel NNAMDI ${ }^{1}$, Maria Esther UJU DIBUA ${ }^{1}$ and Terwase Fabian IKPA ${ }^{2 *}$ \\ ${ }^{I}$ Department of Microbiology, University of Nigeria, Nsukka, P.O. Box 3322 Nsukka, Enugu State, Nigeria. \\ ${ }^{2}$ Department of Biological Sciences, University of Agriculture Makurdi, \\ PMB 2373 Makurdi, Benue State, Nigeria. \\ *Corresponding author, E-mail: terwasefsi@yahoo.com
}

\begin{abstract}
The increasing resistance of Plasmodium falciparum to available antimalarial drugs currently justifies the quest for potential antiplasmodial agents from plants. Picralima nitida is used as a traditional remedy against malaria in Nigeria. In this study, phytochemical constituents of methanolic and aqueous extracts of $P$. nitida fruit pulp were screened, and tested in vitro against 20 clinical isolates of $P$. falciparum using the schizont growth inhibition assay. Acute oral toxicity of each extract was also evaluated in white albino mice. The results showed the presence of alkaloids, anthraquinones, flavonoids, saponins, and tannins in both extracts. Terpenes were only present in the methanolic extract. In vitro growth inhibition of $P$. falciparum by each extract was dose dependent. The methanolic extract exhibited moderate, but higher antimalarial activity with $\mathrm{IC}_{50}=23.33 \pm 0.76 \mu \mathrm{g} / \mathrm{ml}$, compared to the aqueous extract with $\mathrm{IC}_{50}=28.25 \pm 0.95 \mu \mathrm{g} / \mathrm{ml}$. The difference was significant $\left(\mathrm{t}=16.72\right.$, $\mathrm{df}=19, \mathrm{P}<0.001$ ). The $\mathrm{LD}_{50}$ of each extract was $3807 \mathrm{mg} / \mathrm{kg}$ body weight. The moderate antiplasmodial, and toxicity of these extracts, may justify the use of $P$. nitida, fruit pulp for the treatment of malaria in Nigeria.
\end{abstract}

(C) 2015 International Formulae Group. All rights reserved.

Keywords: phytochemical constituents, malaria, inhibitory concentration, lethal dose.

\section{INTRODUCTION}

Malaria is one of the most important infectious diseases in the tropical and subtropical regions of the world. Significant efforts to control, and perhaps eliminate malaria, beginning from the year 2000-2013 have yielded $30 \%$ global reduction in case incidence of malaria, currently estimated at 198 million cases. Also, a 47\% reduction in global mortality, currently estimated at 584,000 deaths has been achieved (WHO, 2014). Despite these significant reductions, malaria continues to be one of the greatest health problems still facing Africa. The global scope of malaria, and the growth of drug resistant Plasmodium falciparum (Noedl et al., 2008; Dondorp et al., 2009; Miotto et al., 2013) have made the need for varied, effective and improved alternative therapies against the disease a necessity. According to WHO (2014), the burden of malaria is heaviest in WHO Africa region, where approximately $90 \%$ of global malaria deaths occur in children $<5$ years old, who account for $78 \%$ of global malaria mortality. 
The endemic nature of malaria in some parts of the world could be attributed to the emergence and spread of drug resistant malaria to many disease endemic parts of the world (Packard, 2014). This unwanted phenomenon has led to treatment failures in many of the conventional antimalarial drugs, with the same threat extended to the most recent effective antimalarial drugs (Noedl et al., 2008; Dondorp et al., 2009; Miotto et al., 2013). Plants have always been considered as valuable sources of medicine against malaria, and other diseases (Bray, 1990; Balunas and Kinghorn, 2005). It is perhaps a common practice to investigate antimalarial activities from medicinal plants, suspected of having such activities against the malaria parasites. This is necessary in order to determine their potentials as sources of new antimalarial agents.

Picralima nitida, family; Apocynaceae (common name; Akuama plant, Igbo; Osi igwe), is a species occurring in Africa's forest regions. The Nigeria Natural Medicine Development Agency (NNMDA) (2008) has noted that the plant has a wide variety of applications, in the Nigerian herbal medicine. Previous reports have shown the activities of $P$. nitida as an antimicrobial (Fakeye et al., 2000), anti-inflammatory (Ezeamuzie et al., 1994), as well as an antiplasmodial agent (Bikii et al., 2007). The antimalarial effects of the bark, leaf, and seed of the plant have been well documented (Iwu and Klayman, 1992; François et al., 1996; Fakeye et al., 2000; Okokon et al., 2007; Adebayo and Krettli, 2011). However, the antiplasmodial potentials of the fruit pulp, the part of the plant usually discarded as not useful has not been well documented. Therefore, the main aim of this study was to determine whether the antimalarial activities associated with other parts of $P$. nitida, were equally present in the fruit pulp of the plant; a part of the plant that is often thrown away.

\section{MATERIALS AND METHODS Collection of plant materials}

Fresh fruits of $P$. nitida plant were collected from Akabor in Oguta local government area of Imo State, Nigeria. The plant was identified by a plant taxonomist at the herbarium section of the International Centre for Ethnomedicine and Drug Development Nsukka and a herbarium specimen of the plant deposited at the centre.

\section{Extraction procedure}

Seeds were extracted from the fruit, and the fruit pulp pulverized using an electrical crusher machine. Two thousand gram of the pulverized seed was subjected to extraction using the soxhlet extractor with 95\% methanol and distilled water as solvents respectively. The different methanolic and aqueous extracts of the fruit pulp of $P$. nitida plant used were each concentrated to dryness using a water bath and weighed. The weighed extracts were then stored in a refrigerator at 4 ${ }^{\circ} \mathrm{C}$ for further experiments.

\section{Phytochemical screening}

Crude methanolic and aqueous extracts of the fruit pulp of $P$. nitida plant were screened for its phytochemical constituents using the method described by Harborne (1998). The plants phytochemical components tested for were alkaloids, anthraquinons, flavonoids, saponins, tannins, steroids and terpenes.

\section{Blood sample collection for in vitro cultivation of Plasmodium falciparum}

Blood samples were collected aseptically from patients at the clinic of National Institute for Pharmaceutical Research and Development (NIPRD) Abuja. The inclusion criteria were patients who had fever, with axillary temperature $\geq 37.5^{\circ} \mathrm{C}$, and had not taken any anti-malarial drugs in the last two weeks. The absence of antimalarial drugs from their system was confirmed by a negative urine test of 4-aminoquinoloines and 
sulfonamides by Dill-Glazko and Lignin test (WHO, 2001). Patients who satisfied these criteria, and gave oral informed consent were screened for $P$. falciparum mono infections. Thick blood films stained with $10 \%$ Giemsa stain for 10 minutes were examined under the microscope to confirm asexual parasitaemia and to estimate parasite density. The acceptable range of parasitaemia was 2000 80,000 asexual parasites $/ \mu 1$ of blood. Methanol fixed thin smears were stained with 3\% Giemsa stain for 30 minutes, and used to confirm mono infections of $P$. falciparum. In each confirmed case, $5 \mathrm{ml}$ of blood were collected into EDTA bottles, the fresh blood plasma were removed and the blood pellets resuspended and washed thrice in RPMI 1640 for in vitro cultivation of malaria parasites (Flyg et al., 1997).

\section{Preparation of complete malaria culture medium}

The complete malaria culture medium (CMCM) was prepared by dissolving $10.43 \mathrm{~g}$ of RPMI 1640 powder (Gibco), $6 \mathrm{~g}$ of Hepes and $2 \mathrm{~g}$ of $\mathrm{NaHCO}_{3}$ in litre of distilled demonized water. The solution was filtered using $0.22 \mu \mathrm{m}$ membrane filters and $0.5 \mathrm{ml}$ Gentamycin (from $50 \mathrm{mg} / \mathrm{ml}$ stock) was added. The mixture was then stored at $4{ }^{\circ} \mathrm{C}$ in aliquots of $45 \mathrm{ml}$. Before parasite cultivation, each aliquot was supplemented with 5\% albumax II solution (Cranmer et al., 1997).

\section{Preparation of stock solution of extracts' of Picralima nitida}

Stock solutions of both methanolic and aqueous extracts were each prepared by dissolving $20 \mathrm{mg}$ of the extract in $10 \mathrm{ml}$ dimethylsulphoxide (DMSO) and sonicated for 30 minutes to yield a $20 \mathrm{mg} / 10 \mathrm{ml}$ stock solution of the extracts. The stock solution was stored at $4{ }^{\circ} \mathrm{C}$ until used, during in vitro drug susceptibility test of the extracts against $P$. falciparum parasites.
In vitro cultivation of $\boldsymbol{P}$. falciparum isolates and susceptibility test with extracts of Picralima nitida

The assay was performed in duplicates, using a modification of WHO's schizont growth inhibition method (WHO, 2001). Briefly, $200 \mu \mathrm{l}$ of a mixture of CMCM and $P$. falciparum positive blood from each individual patient, $n=20$ was distributed in duplicates, on 96 well flat bottom micro titre plates. Then $200 \mu \mathrm{l}$ of the stock solution was used to make a 7 well, two fold serial dilution of each sample, bringing the final plate concentration range of 3.13- $200 \mu \mathrm{g} / \mathrm{ml}$. The $8^{\text {th }}$ well was maintained as control with a mixture of CMCM and P. falciparum positive blood without the extract. The plates were incubated at $37{ }^{\circ} \mathrm{C}$ in a candle jar under $\mathrm{CO}_{2}$ atmosphere for 30 hours. After incubation, the plates were tilted at an angle, allowed to settle and $5 \mu \mathrm{l}$ content drawn from the bottom of each well was removed. The cell content from each well was used to form a series of thick films on clean microscopy slides, and stained with $2.5 \%$ Giemsa stain for 45 minutes. The number of schizonts formed per 200 asexual parasites were counted and recorded from the control wells, as well as the wells containing the extracts (WHO, 2001).

\section{Determination of $\mathrm{IC}_{50}$ of Picralima nitida extracts}

The number of schizonts counted from the extract free control wells, and the wells with extracts from each cultured isolate were fed into a specialized malaria in vitro inhibitory concentration determination software, HN-NonLin. The concentrations required to inhibit schizont maturation by $50 \%, 90 \%$ and $95 \%$ were then determined. $\mathrm{HN}-\mathrm{Non}$ Lin is available free of charge at http://malaria.farch.net.

\section{Experimental animals}

The animals used for acute toxicity test were adult male white Albino mice weighing 22-30 g. The mice were obtained from the animal house of the University of Nigeria Nsukka. They were housed in standard cages, 
and were handled according to local rules and regulation of Experimental Animals at the University of Nigeria, Nsukka, Nigeria.

\section{Acute toxicity test}

The acute toxicity of $P$. nitida extracts in mice was carried out as reported by Lorke (1983) with a slight modification. A total of 24 male white albino mice were divided into 2 sets of 6 groups of 2 mice each. The mice were treated orally with single doses of 10 , $100,1000,1600,2900,5000, \mathrm{mg} / \mathrm{kg}$ body weight. Both the methanolic and aqueous extracts of the fruit pulp were separately administered after the mice were starved for 24 hours. Two additional mice were only given distilled water as control animals. The animals in each group were routinely inspected for appearance or signs of toxicity such as, weakness, falling off of hair, coma or even death for a period of 24 hours.

\section{Determination of $\mathrm{LD}_{50}$ of Picralima nitida extracts}

Lethal dose $\mathrm{LD}_{50}$ of each extract was estimated by calculating the geometric mean of the maximum dose with $0 \%$ mortality and the minimum dose with $100 \%$ mortality (Lorke, 1983).

\section{Statistical analysis}

Inhibitory concentrations (ICs) of the two extracts were compared by paired sample t-test, using SPSS software version 20, IBM Inc. 2011. The level of significance $(\alpha)$ was $=$ 0.05 .

\section{RESULTS}

The phytochemical screening of the aqueous and methanolic extracts from the fruit pulp of $P$. nitida revealed the presence of alkaloids, anthraquinones, flavonoids, saponins, tanins, and terpenes (Table 1). Steroids were absent in both extracts, while terpenes were present in the methanolic extract but absent in the aqueous extract.

Each of the extract produced a dose dependent inhibitory activity against clinical parasite isolates of $P$. falciparum at the different concentrations used. Of the two, the methanolic extract showed a comparably higher antimalarial activity, with mean $\mathrm{IC}_{50}$ of $23.33 \pm 0.76 \mu \mathrm{g} / \mathrm{ml}$, compared to the aqueous extract with $\mathrm{IC}_{50}$ of $28.25 \pm 0.95 \mu \mathrm{g} / \mathrm{ml}$. The mean $\mathrm{IC}_{50}$ values of the two extracts were significantly different $(\mathrm{t}=16.72, \mathrm{df}=19, \mathrm{P}<$ 0.001). The difference was consistently significant at higher inhibitory concentrations - $\mathrm{IC}_{90}$ and $\mathrm{IC}_{95}$ (Table 2).

The acute oral toxicity of both the methanolic and aqueous extracts of the fruit pulp of $P$. nitida demonstrated that a dose of $5000 \mathrm{mg} / \mathrm{kg}$ produced physical signs of toxicity in white albino mice 10 hours after administration of the extracts, leading to death. These signs included writhing, decreased motor activity, gasping and subsequently death. All the animals treated with $5000 \mathrm{mg} / \mathrm{kg}$ body weight of the extracts died. The $\mathrm{LD}_{50}$ of each extract was therefore estimated to be $=3705.15$ (Table 3).

Table 1: Phytochemicals present in the fruit pulp of Picralima nitida extracts.

\begin{tabular}{lcc}
\hline Phytochemicals & Methanolic extract & aqueous extract \\
\hline Alkaloids & + & + \\
Anthraquinones & + & + \\
Flavonoids & + & + \\
Saponin & + & + \\
Tannins & + & + \\
Terpens & + & - \\
\end{tabular}

$+=$ present, $-=$ absent 
Table 2: Mean inhibitory concentrations (ICs) of extracts of $P$. nidita in $\mu \mathrm{g} / \mathrm{ml} \pm \mathrm{SD}$.

\begin{tabular}{llllll}
\hline ICs & Methanolic extract & Aqueous extract & t - test & Df & P - value \\
& & & & & \\
\hline $\mathrm{IC}_{50}$ & $23.33 \pm 0.76$ & $28.25 \pm 0.95$ & 16.72 & 19 & $<0.001$ \\
$\mathrm{IC}_{90}$ & $92.53 \pm 1.01$ & $110.42 \pm 1.29$ & 51.11 & 19 & $<0.001$ \\
$\mathrm{IC}_{95}$ & $116.57 \pm 1.17$ & $138.60 \pm 14.32$ & 6.79 & 19 & $<0.001$ \\
\hline
\end{tabular}

Table 3: Lethal Dose (LD) $)_{50}$ of fruit pulp extracts of $P$. nitida.

\begin{tabular}{lc}
\hline Type of extract & $\mathbf{L D}_{\mathbf{5 0}}$ \\
\hline Methanolic extract & 3705.15 \\
Aqueous extract & 3705.15 \\
\hline
\end{tabular}

\section{DISCUSSION}

Phytochemical compounds found in plants are reported to act in synergy with nutrients and dietary fibre to protect against diseases. Compounds such as terpenoids are commonly implicated in the antiprotozoal and antiplasmodial activities of many plants that have being studied (Phillipson and Wright, 1991; Asase et al., 2004). A notable example of a terpenoid from plant is artemisinin, the main active ingredient in the traditional Chinese antimalarial qinghaosu (Tan et al., 1998). Currently, artemisinin derivatives in combination with other antimalarial compounds are the most effective antimalarial drugs recommended for the treatment of malaria (WHO, 2010). In one study, flavonoids were reported to show significant anti-parasitic activities against different strains of malaria, trypanosomes and leishmania (Kim et al., 2004). The presence of these phytochemical compounds in the fruit pulp extracts of $P$. nitida suggest that perhaps, these compounds may be acting in synergy with one or more compounds to exert the observed antimalarial activity, albeit moderate, as seen from the fruit pulp extracts of $P$. nitida. The absence of terpenoids in the aqueous extract despite its presence in the methanolic extract could be the in ability of water to extract the compound due to its non- polar nature (Bhat et al., 2005). Perhaps its presence in the methanolic extract could be a reason why the extract exhibited moderately higher antimalarial activity in vitro compared to the aqueous extract.

Both in vivo and in vitro antiplasmodial activities of ethanolic extracts of $P$. nitida plant have been reported (Iwu and Klayman, 1992; Okokon et al., 2007). One of the studies linked the antiplasmodial activities of the various parts of the plant to indole alkaloids present in the plant (Iwu and Klayman, 1992). Alkaloids were also found in both the aqueous and methanolic extracts of the fruit pulp of $P$. nitida in the present study. The latter extract with an $\mathrm{IC}_{50}$ of $23.33 \pm 0.76 \mu \mathrm{g} / \mathrm{ml}$ exhibited moderate, but significantly higher antimalarial activity on clinical isolates of Plasmodium falciparum compared to the former's IC $_{50}$ of $28.25 \pm 0.95$ which was also moderate. The threshold classification of the present in vitro antimalarial activities of extracts from the pulp of $P$. nitida seeds was based on the classification according to Gessler et al. (1994), which classified extracts with $\mathrm{IC}_{50}$ less than $10 \mu \mathrm{g} / \mathrm{ml}$ as very good; 10 $50 \mu \mathrm{g} / \mathrm{ml}$ as moderate and over $50 \mu \mathrm{g} / \mathrm{ml}$ as having low activity. In one study the Cameroon, the antimalarial activity of the methanolic extract of $P$. nitida against chloroquine resistant W2 strain of $P$. 
falciparum was over 2 fold higher $\left(\mathrm{IC}_{50}=\right.$ $10.90 \pm 1.10)$ than the values recorded in this study (Bikii et al., 2007). However, the part of the plant used was not clearly stated. Our knowledge of the various inhibitory activities of $P$. nitida extracts from different parts of the plant on $P$. falciparum indicated a death of data on extracts from the fruit pulp. This study has shown moderate activity using methanol as the extracting solvent. The antimalarial activity of the aqueous extract in the present results which also showed a moderate activity was in agreement with the results obtained by Iwu and Klayman (1992), as well as François et al. (1996) with various parts of the plant.

The acute toxicity potential of both the methanolic and aqueous extracts of the fruit pulp of $P$. nitida in white albino mice showed moderate toxicity (Homburger, 1989) with $\mathrm{LD}_{50}=3807 \mathrm{mg} / \mathrm{kg}$ body weight. A recent study by Solomon et al. (2014) observed that ethanolic extracts of $P$. nitida seeds induced toxic effects on the testis of male adult Wistar rats, which led to a reduction in the seminal fluid parameters of the rats. Our study did not investigate a similar histopathological effect on mice, but it reminds one of the toxic effects the plants' extracts might bring to bear on body organs. Such a distortion is capable of compromising the fertility potentials of the rats. However, it appears that reduction in the seminal fluid of rats by some herbal extract might be a common attribute of herbs which exhibit antimalarial properties (Raji et al., 2003; Oze et al., 2006). A similar property has been observed in some standard antimalarial drugs, like chloroquine and halofantrine (Adeeko and Dada 1993; Orisakwe et al., 2003). These drugs were used extensively in the treatment of malaria without necessarily compromising human fertility.

The fruit pulp of $P$. nitida is not always considered useful by those who frequently utilize the plant. Consequently, it is frequently thrown away. Our finding has demonstrated the medicinal value of this part of the plant with some antimalarial activity, albeit moderate in nature. However the moderate toxicity also recorded in the fruit pulp may justify the future use of this plant's part as a complementary remedy for the treatment of malaria.

\section{ACKNOWLEDGMENTS}

We wish to thank $\mathrm{Mr}$ and Mrs S. Nwodo for their financial support toward this work. We are also grateful to the staff of the University of Nigeria, Nsukka; and National Institute for Pharmaceutical Research and Development Abuja, Nigeria for their technical support.

\section{REFERENCES}

Adebayo JO, Krettli AU. 2011. Potential antimalarials from Nigerian plants: a review. J. Ethnopharmacol., 133: 289302.

Adeeko AO, Dada OA. 1993. Chloroquine reduces the fertility capacity of epididymal sperm in rats. Afr. J. Med. Sci., 27: 63-68.

Asase A, Akwetey GA, Achel DG. 2004. Ethnopharmacological use of herbal remedies for the treatment of malaria in the Dangme West District of Ghana. J. Ethnopharmacol., 129: 367-376.

Balunas MJ, Kinghorn AD. 2005. Drug Discovery from Medicinal Plants. Life Sci., 78: 431-441.

Bikii J, Tchouya GRF, Tchouankeu JC, Tsambo E. 2007. Antimalarial activity in crude extracts of some Cameroonian medicinal plants. Afr. J. Trad. Complement., Alternate. Med., 4(1): 107111.

Bhat SV, Nagasampagi BA, Sivakumar M. 2005. Chemistry of Natural Products. Narosa Publishing House: India.

Bray DH, Warhurst DC, Connolly JD, O'Neill MJ, Phillipson JD. 1990. Plants as sources of antimalarial drugs. Part 7 . Activity of some species of Meliaceae and their constituent limonoids. Phytother. Res., 4: 29-35.

Cranmer SL, Magowan C, Liang J, Coppel RL, Cooke BM. 1997. An alternative to 
serum for the cultivation of Plasmodium falciparum in vitro. Trans. R. Soc. Trop. Med Hyg., 91(3): 363-365.

Dondorp AM, Nosten F, Yi P, Das D, Phyo AP, Tarning J, Lwin KM, Ariey F, Hanpithakpong W, Lee SJ, Ringwald P, Silamut K, Imwong M, Chotivanich K, Lim P, Herdman T, An SS, Yeung S, Singhasivanon P, Day NPJ, Lindegardh N, Socheat D, White NJ. 2009. Artemisinin resistance in Plasmodium falciparum malaria. N. Engl. J. Med., 361: 455-467.

Ezeamuzie IC, Ojinnake MC, Uzygna EO, OJI SE.1994. Anti-inflammatory, antipyretic and antimalarial activity of a West African medicinal plant-Picralima nitida. Afr. J. Med. Med. Sci., 23(1): 8589.

Fakeye TO, Itiola OA, Odelola HA. 2000. Evaluation of the antimicrobial property of the stem bark of Picralima nitida (Apocynaceae). Phythother. Res., 14: 368-370.

Flyg BW, Perlmann H, Perlmann P, Esposito F, Berzins K. 1997. Wild isolates of Plasmodium falciparum. Clin. Exp. Immunol., 107: 321-327.

François G, AkéAssi L, Holenz J, Brungmann G. 1996. Constituents of Picralima nitida display inhibitory activities against asexual erythrocytes forms of Plasmodium falciparum in vitro. $J$. Ethnopharmacol., 54(2-3): 113-117.

Gessler MC, Nkunya MHH, Mwasumbi LB, Heinrich M, Tanner M. 1994. Screening Tanzanian medicinal plants for antimalarial activity. Acta. Trop., 56: 6567.

Harborne JB. 1998. Phytochemical Methods. A Guide to Modern Techniques of Plant analysis. Chapman and Hall LTD. London Great Britain.

Homburger F. 1989. In vitro testing in the study of toxicity and safety evaluation. In A Guide to General Toxicology (2 Revised edn). Karger: New York; 198.
Iwu MM, Klayman DL. 1992. Evaluation of the in vitro antimalarial activity of Picralima nitida extracts. $J$. Ethnopharmacol., 36: 133-135.

Kim YC, Kim H, Wataya Y, Sohn DH, Kang TH, Kim MS, Kim YM, Lee G, Chang J, Park H. 2004. Antimalarial activity of lavandulyl flavanones isolated from the roots of Sophora flavescens. Biol. Pharm. Bull., 27: 748-750.

Lorke D. 1983. A new approach to practical acute toxicty testing. Arch. Toxicol., 54: 275-287.

Miotto O, Almagro-Garcia J, Manske M, Macinnis B, Campino S, Rockett KA, et al. (2013) Multiple populations of artemisinin-resistant Plasmodium falciparum in Cambodia. Nat. Genet., 45: 648-655.

Nigeria Natural Medicine Development Agency (NNMDA). 2008. Medicinal Plants of Nigeria, North Central Zone. Federal Ministry of Science and Technology: Nigeria; 120.

Noedl H, Se Y, Schaecher K, Smith BL, Socheat D, Fukuda MM. 2008. Evidence of artemisinin-resistant malaria in western Cambodia. N. Engl. J. Med., 359: 26192620.

Okokon JE, Antia BS, Igboasoiyi AC, Essien EE, Mbagwu HO. 2007. Evaluation of antiplasmodial activity of ethanolic seed extract of Picralima nitida. J. Ethnopharmacol., 111: 464-467.

Orisakwe OE, Obi HE, Udemezue OO. 2003. Effect of halofantrine on testicular architecture and testosterone level in guinea pigs. Eur. Bull. Drug. Res., 11: 105- 109.

Oze G, Nwanjo H, Oze R, Akubugwo E, Orisakwe E, Aka P. 2006. Reproductive impairment associated with the ethanolic extract of Alstonia boonei (De-Wild) stem bark in male rats. Int. J. Third World Med., 6(1).

Packard RM. 2014. The origins of antimalarial drug resistance. N. Engl. J. Med., 371: 397-399. 
Phillipson JD, Wright CW. 1991. Antiprotozoal compounds from plants sources. Planta Med., 57: S53-S59.

Raji SY, Udoh US, Mewoyeka OO, Ononye FC, Bolarinwa AF. 2003. Implication ofreproductive endocrine malfunction in male antifertility efficacy Azadirachta indica extract in rats. Afr. J. Med. Sci., 32: 159- 165.

Solomon IP, Oyebadejo SA, Edet IE, Idiong Jr JU, Ebong AO. 2014. Chronic oral consumption of ethanolic extracts of Picralima nitida (Akuamma) induced gross morphological and seminal alterations on the testes of adult wistar rats. J. Chem. Bio. Phy. Sci SecB., 4(4): 3464-3475.

Tan RX, Zeng WF, Tang HQ. 1998. Biologically active substances from the genus Artemisia. Planta Med., 64: 295302.

WHO (World Health Organization). 2001. In vitro micro test (Mark III) for assessment of the response of Plasmodium falciparum to chloroquine, mefloquine, quinine, amodiaquine, sulfadioxine/ pyrimethamine, and artemisinin. CTD/ MAL/97.20, World Health Organization.

WHO (World Health Organization). 2010. Guidelines for the Treatment of Malaria $\left(2^{\text {nd }}\right.$ edn). WHO Press, World Health Organization: Geneva, Switzerland.

WHO (World Health Organization). 2014. World Malaria Report 2014. WHO Press, World Health Organization: Geneva, Switzerland. 